\title{
CONSIDERAC̣ÕES SOBRE A ORIGEM DOS GRÃOS "OLHOS-DE-QUARTZO" NAS ROCHAS PORFIROIDAIS DO DISTRITO DE WESTERN MINES, ILHA DE VANCOUVER, CANADÁ
}

\author{
ILSON GUIMARÃES CARVALHO*
}

\begin{abstract}
Quartz-eye bearing porphyroidal rocks occur in straight association with the vent ore, in the vent zone, of the base metal massive sulphide deposits of the Western Mines District. Microscopic observations on these rocks indicated two stages of quartz-eye development, which are part of a continuous process of rock alternation. In the earlier stage (first generation quartz) there was a total or quasi-total replacement of chloritecalcite spherulites or a filling of vesicles by quartz. It was accompanied by development of strong vertical foliation which superimposed to the primary bedding. In the final stage (second generation quartz) the quartz overprinted the vertical schistosity, and deformation was minimum.

Quartz-eye typical of the earlier stage, termed first generation quartz, is surrounded by a bowed micaceous matrix; this is not the case when it is examined in a section perpendicular to the foliation. Composite grains and recrystallized single round grains may be in association with deformed or broken grains of original quartz and with latter or second generation quartz-eye grains. A preserved nucleus of calcite is occasionally observed.

Hypidiomorphic and idiomorphic coarse grains of quartz are typical of the final fase of the vent alteration process, they are termed second generation quartz. Overgrowth of second generation quartz without optical character of continuity upon first generation quartz is commonly observed. In addition most of the round rims of quartz represent the outer zone of the crystallized second generation quartz. It becomes distinguishable from the rest of the quartz grain because of the abundance of microinclusions.

Since both stages of quartz generation affected either mafic-intermediate or intermediate-acidic rocks, it is suggested that the term "quartz-eye bearing porphyroidal rocks" might be better regarded as a textural terminology than a compositional one.
\end{abstract}

INTRODUC̣Ão O termo quartz-eye bearing porphyroidal rocks, cujo correspondente em português literalmente seria rochas porfiroidais com olhos-dequartzo, foi sugerido por Hopwood (1976) para os tipos de rochas porfiroidais ácidas portadoras de uma textura caracteristicamente definida por "olhos-de-quartzo". Hopwood observou ser importante a freqüente associação estratigráfica de tais tipos de rochas com os depósitos de sulfetos maciços vulcanogênicos.

O material discutido no presente trabalho é bastante similar, seja no ponto de vista textural como também estrutural, com os materiais estudados por Hopwood, que também considerou o fato de que the repeated common petrographic features implicam uma origem comum (Hopwood, op. cit., p. 601). Em nosso caso, algumas evidências são sugestivas de que as rochas porfiroidais com olhos-de-quartzo foram formadas por um processo metassomático devido à contínua alteração hidrotermal que afetou as rochas do conduto vulcânico durante todo o tempo em que se processava a mineralização de sulfetos.

\section{FEIÇÕES GEOLÓGICAS GERAIS DO DISTRITO MINEIRO DE WESTERN MINES}

$O$ Distrito de Western Mines abrange uma área de cerca de $49 \mathrm{~km}^{2}$ que se situa entre as latitudes $49^{\circ} 32^{\prime}-49^{\circ} 35^{\prime} \mathrm{N}$ e longitude $125^{\circ} 32^{\prime}-125^{\circ} 39^{\prime} \mathrm{W}$, sul a sudoeste dos limites meridionais do Lago Buttle, na itha de Vancouver, no Canadá (Fig. 1).

As rochas hospedeiras dos corpos de sulfetos consistem em rochas vulcânicas do tipo arco-de-ilhas e rochas sedimentares vulcaniclásticas relacionadas. Tais rochas compðem a formação Youbou, uma parte do grupo Sicker, do período Permiano. Na área das minas, a formação Youbou é dividida em três unidades denominadas pelo autor Tuff, Vent e, a mais nova, Lapilli-Tuff. A unidade Tuff flanqueia a unidade Vent que, espacialmente, ocupa o conduto vertical vulcânico. Ambas são parte de um único ciclo vulcânico que se processou em condiçðes subaquáticas de pouca profundidade (Carvalho, 1979).

Corpos de sulfeto maciço e, subordinadamente, de sulfeto disseminado ocorrem tanto na unidade Vent como na parte mais superior da unidade Tuff e são, respectivamente, denominados minério do conduto (vent type ore) e minério do flanco (flank type ore) (Fig. 2).

As rochas porfiroidais com olhos-de-quartzo estão na unidade Vent e são de composição quartzo-sericítica e gradam lateralmente em um tipo "não-bandado" de quartzo-sericita-cloritaxisto com teores variáveis de $0 \%$ a $20 \%$ de epídoto e calcita. Esse tipo de rocha "nãobandado" gradualmente passa para os xistos bandados

* Programa de Pesquisa e Pós-Graduação em Geofísica/PPPG/UFBA, Instituto de Geociências da UFBA, Rua Caetano Moura, 123, Federação, CEP 40000, Salvador, Bahia 


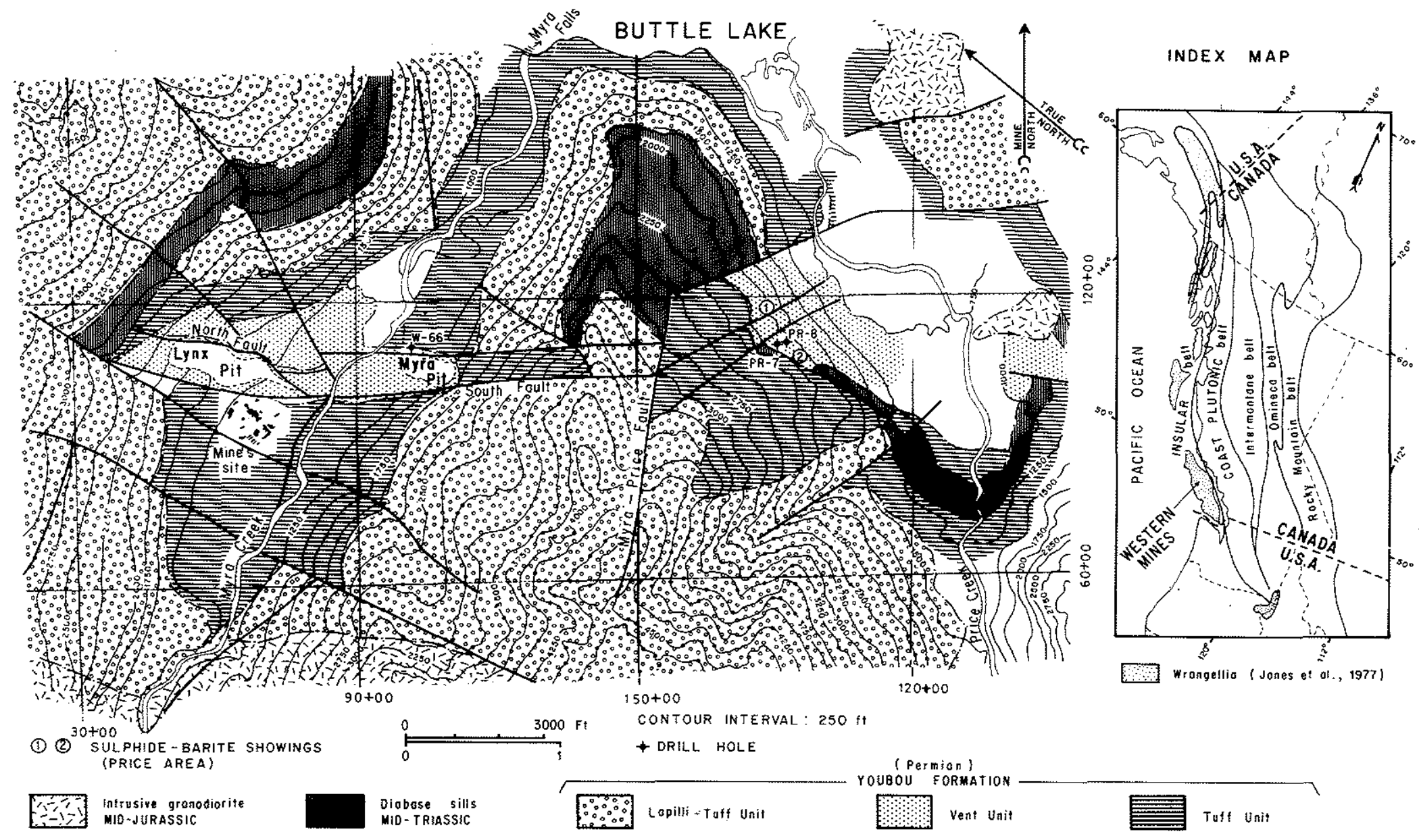




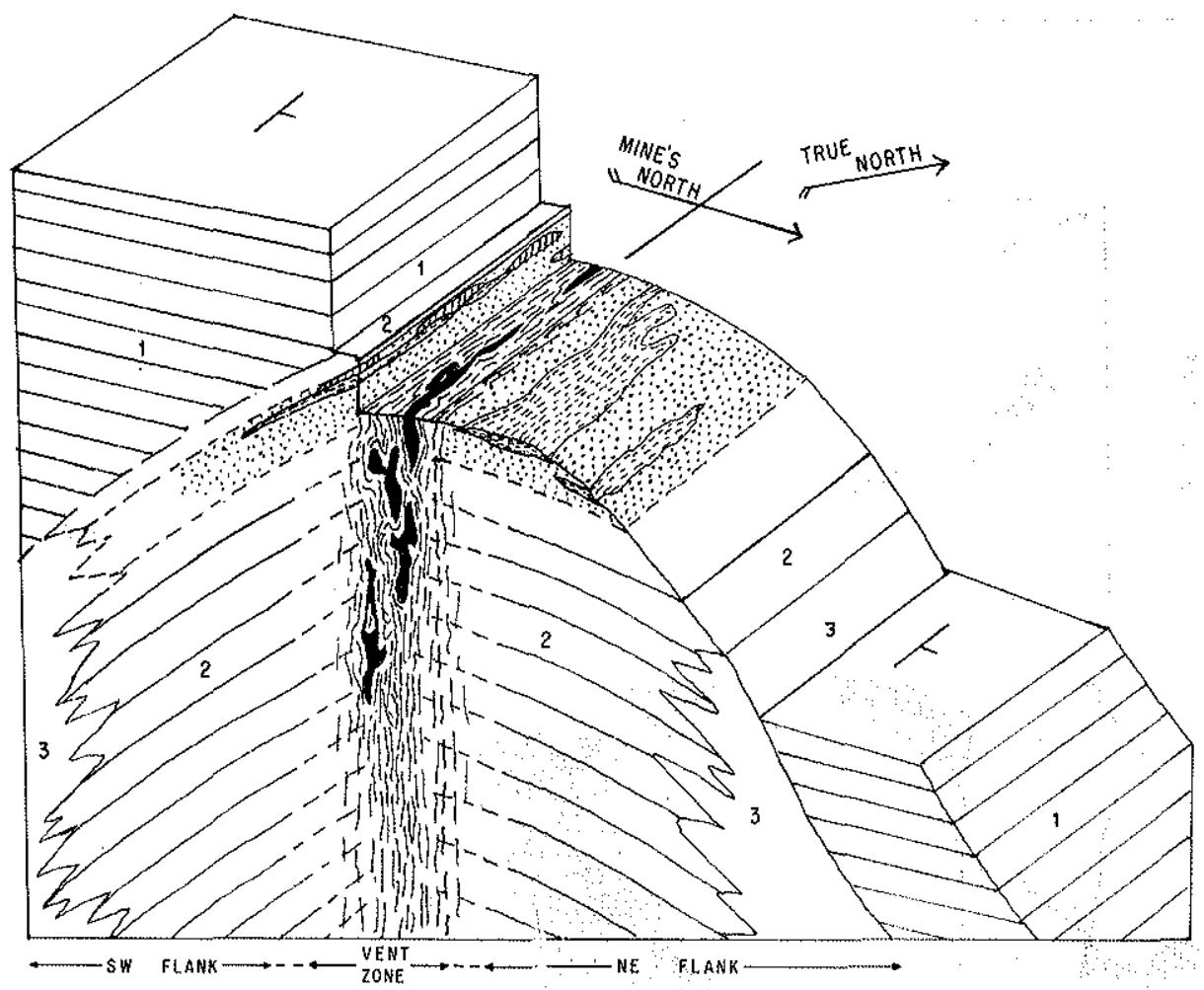

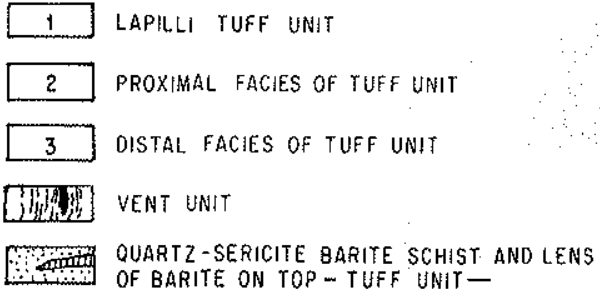

Figura 2 - Litologias presentes no Distrito de Western Mines

de composição de clorita, calcita e epídoto, com teores menores de quartzo e sericita, que representam os principais tipos litológicos da unidade Tuff nas proximidades do conduto e constituem o fácies proximal que flanqueia a zona do conduto e são portadores do minério do flanco (Carvalho, 1979).

Seraphim et al. (1978) observou que, no Distrito, os depósitos (Lynx, Myra e Price) estão linearmente distribuídos, de direçáo $\mathrm{N}^{\circ} 5^{\circ} \mathrm{W}$, ocorrendo ao longo das rochas vulcânicas bastante alteradas do conduto, constituindo uma zona de espessura variável de até $70 \mathrm{~m}$ e de profundidade que atinge $400 \mathrm{~m}$. Tal zona de alteraçăo do conduto é, em muitos locais, portadora de uma foliação vertical bem desenvolvida que lhe dá a aparência de ter sido submetida a um intenso cisalhamento (Carvalho, 1979).

\section{PRINCIPAIS FEIÇÕES PETROGRÁFICAS DAS ROCHAS PORFIROIDAIS COM OLHOS-DE- QUARTZO E TIPOS ASSOCIADOS}

Embora olho-de-quartzo seja uma feição comum em rochas da unidade Vent, ele pode ser observado, menos

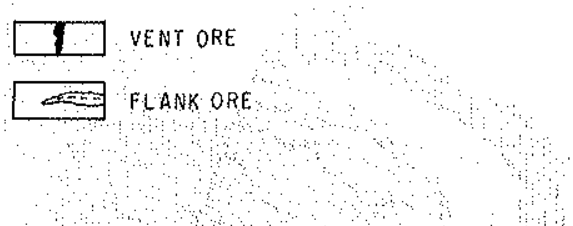

Bloco diagrama e morfología idealizada das unidades. frequentemente, na unidade Tuff, próximo das partes mais superiores do conduto, em rochas de composiçăo de quartzo, sericita e barita. A maioria dos espécimes estudados, como os das Figs. 3 e 4, e proveniente da unidade Vent. As fotomicrografias e os esquemas apresentados foram selecionados para ilustrar todo o processo de formação dos grãos olhos-de-quartzo. Tal processo é fundamentalmente considerado em dois estágios de desenvolvimento denominados inicial e final (Figs. 5 a 26). Como abordaremos adiante, o processo de formação não foi especialmente de todo homogêneo. Rochas consideradas afetadas pelo estágio inicial, na verdade, podem ter sido as parcialmente afetadas pelo processo, ou seja, cujo processo atuou com menor intensidade, ou em um período de tempo menor, que sobre as outras bastante silicificadas que tipificam o material em discussão e são consideradas afetadas por ambos os estágios inicial e final.

Na unidade Vent, os tipos litológicos principais são de composição quartzo-sericítica. Algumas variedades afaníticas sã̃o muito pobres em grâos olhos-de-quartzo. Tais variedades são portadoras de vênulas e lentezinhas de quartzo, e de manchas quartzíticas contendo traços 


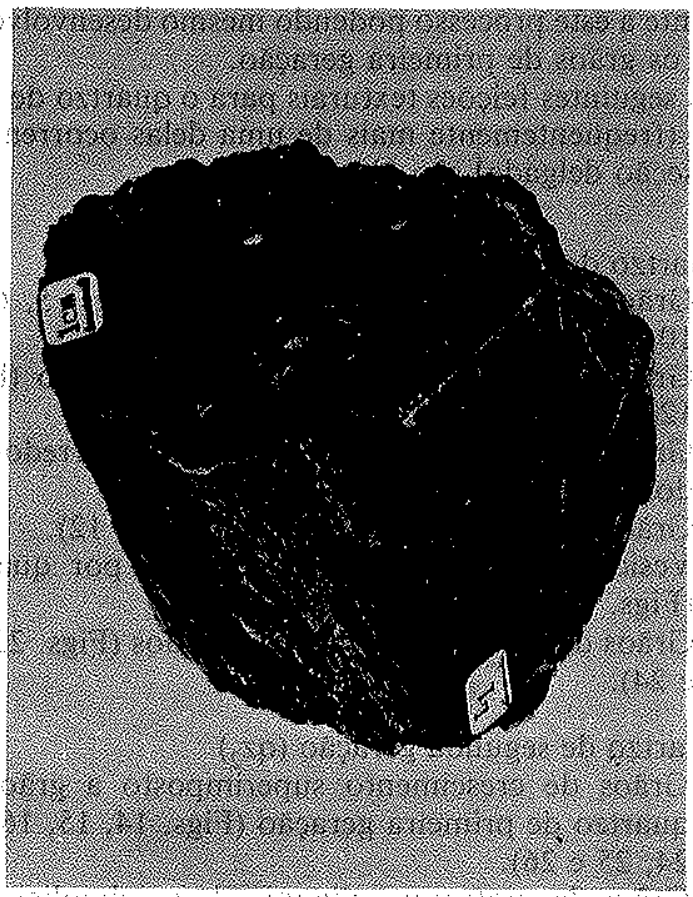

3

Figura 3 - Xisto porfiroidal com olho-de-quartzo: O rótulo indica a direção de orientação textural (lineação de xistosidade) no plano vertical e perpendicular ao plano de xistosidade que é também vertical (maiores detalhes na:Fig. 30). Amostra LOP 13.A (GHK) coletada na mina Lynx, zona do open pit

de sericita intersticial aos finos grãos de quartzo. As variedades porfíroidais são petrograficamente caracterizadas por vesículas, esféricas quando não deformadas, de diâmetro variável, raramente maior que $1 \mathrm{~mm}$ e preenchidas por quartzo. Em algumas amostras não muito silicificadas, um núcleo de calcita fina pode ser observado no interior dessas vesículas. A abundância de esferulitos dá origem a uma textura esferulítica normalmente xistosa. $\mathrm{O}$ quartzo presente nesses esferulitos exibe diferentes graus ou estágios de recristalização. Ele é normalmente de granulação fina, aproximadamente de 0,08 a 0,05 mm na máxima dimensão. $O$ aumento da recristalização é denotado pelo incremento do tamanho desses grãos o que faz com que o número de grãos por esferulito decresça. Foi observado que a recristalização cresce em direção às porções mais interiores do conduto, em direção ao minério do conduto, e de tal forma que, em alguns casos, um único grão de quartzo por esferulito é observado. Olhós-de-quartzo são tipicamente visualizados quando esses esferulitos são conformavelmente circundados pela matriz micácea. Tal feição, como voltaremos a falar adiante, é mais bem observada em determinadas seçðes dos tipos mais silicificados; onde os grãos esféricos ou alongados de quartzo são normal. mente circundados por quartzo opticamente nåocontínuos e, em alguns casos, observa-se um anel de quartzo em condiçðes de continuidade óptica com o

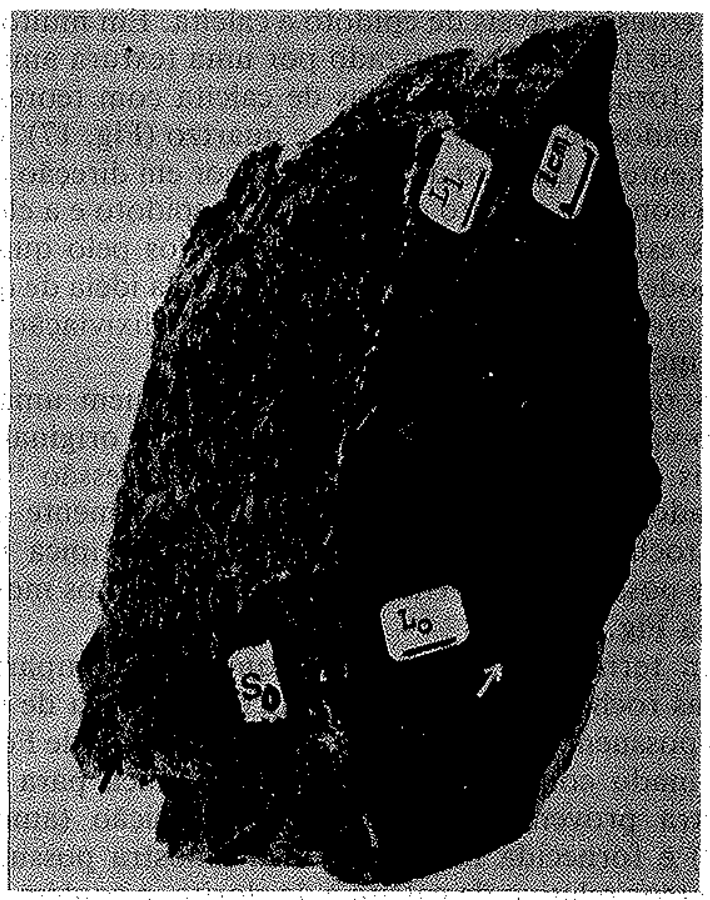

4

Figura 4 - Xisto porfiroidal com olho-de-quartzo de mesma proveniência que a amostra LOP 13.A (GHK). Notar a discordância entre 0 acamamento preservado $\left(S_{0}-L_{0}\right)$ de granulação fina e a xistosidade $\left(S_{1}-L_{1}\right)$. A seta branca indica um grão olho-de-quartzo cujo desenvolvimento foi responsável pela deformação do acamamento de grã-fina. As setas pretas indicam zonas de autobrechação nas camadas

grão de quartzo. Na maioria dos casos examinados, tais anéis mostraram-se, pela consistência, representar a zona exterior dos últimos grãos de quartzo formados. Esta zona torna-se distinta do resto do grão pela abundância de microinclusões nela contida.

$O$ teor de sulfetos, geralmente, é menor que $15 \%$. Em torno desses valor, ou acima, o material quartzo-sericítico normalmente constitui um tipo de minério stockwork de $\mathrm{Cu}-\mathrm{Pb}-\mathrm{Zn}$ e que é explorado devido à proximidade com os corpos lenticulares de sulfeto maciço ou com um tipo de minério semimaçço bastante rico em quartzo.

Mineralogicamente, as rochas da unidade Vent possuem as seguintes características: $a$ ) o teor de clorita, calcita e epídoto cresce em direção ao flanco, ou seja, em direção à unidade Tuff; $b$ ) barita é raramente obser. vada; e $c$ ) os exemplos mais típicos de rochas porfiroidais com olhos-de-quartzo possuem $<5 \%$ de clorita $\mathrm{e}$ epídoto, cada, e $<1 \%$ de calcita e barita, cada. A composição química não é, pois, bem definida e as diversas análises mostram valores próximos dos da Tab. 1 - eles apresentam variações a depender do maior grau de alteração em que Si e $\mathrm{K}$ aumentam, $\mathrm{Mg}$, Ca e Fe não combinado com S diminuem (Carvalho, 1979).

A zona de transição (transitional zone, Fig. 2) entre as unidades Vent e Tuff é caracterizada pela presença de uma rocha xistosa composta de quartzo, sericita e clori- 
ta, e teores variáveis de epídoto e calcita. Em muitos locais, esse tipo é caracterizado por uma textura amigdaloidal formada por esférulas de calcita com teores subordinados de clorita, epídoto e quartzo (Fig. 17). Gradualmente, o quartzo aumenta em teor em direção a zona do conduto. $O$ fato de a calcita, o epídoto e a clorita nesses esferulitos terem sido substituídos pelo quartzo não pode então ser desaprovado diante da idéia de que a sílica cresceu em vazios produzidos pela lixiviação desses minerais.

As rochas da zona de transição possuem uma foliação vertical que mascara o bandamento original que é, pois, dificilmente observado, daí a expressão "nãobandado" já usada. No conduto propriamente dito, uma rocha porfiroidal a olho-de-quartzo típica raramente possui bandamentos reliquiares como os mostrados na Fig. 4.

Em termos de composição química, comparadas com as rochas do conduto, as rochas da zona de transição possuem teores maiores de $\mathrm{Na}, \mathrm{Ca}, \mathrm{Mg}$ e de $\mathrm{Fe}$ não combinado com S. A composição química para uma amostra proveniente da zona de transição (amostra M.12) é fornecida na Tab. 1. Tal amostra possui um baixo teor relativo de calcita e de clorita, e contém esferulitos parcialmente substituidos por quartzo.

No presente trabalho, chamamos de quartzo de primeira geração (para simplificar, $\mathrm{qz}_{1}$ ) aquele que, localmente, indica uma origem por substituição imediata de minerais de rocha preexistentes; e de quartzo de segunda geração (para simplificar $q z_{2}$ ) aquele que seria sub- sequiente a este processo podendo mesmo desenvolver-se sobre os grãos de primeira geração.

As seguintes feições texturais para o quartzo de alteração (freqüentemente mais de uma delas ocorrem em uma seção delgada) são observadas:

1. Quartzo de primeira geração $\left(q z_{1}\right)$

a) Grãos redondos ou arredondados (Figs, 5, 6, 7, $10,11,12,14,15,16,18 d, 20,25$ e 26 ).

b) Grãos olhos de contorno subpoligonizado (Figs. 12,16 e 19).

c) Grãos compostos arredondados e subarredondados (Figs. 8, 11, 13, 21 e 25).

d) Grãos de feiçôes irregulares (Figs, 6 e 12),

e) Vesículas parcialmente substituídas por quartzo (Figs. 9, 17 e 18a).

f) Grãos deformados e grãos alongados (Figs. 22, 23 e 24).

2. Quartzo de segunda geração $\left(\mathrm{qz}_{2}\right)$

a) Grãos de crescimento superimposto a grãos de quartzo de primeira geração (Figs. 14, 15, 16, 20, 24,25 e 26 ).

b) Grãos de contorno poligonizado a subpoligonizado (Figs. 15 e 27).

c) Grãos compostos em associação com quartzo primário (original) (Fig. 21).

d) Campos quartzíticos muitas vezes alongados ou de formas achatadas discordantes ou subconcordantes com a xistosidade.

Tabela 1 -

\begin{tabular}{|c|c|c|c|c|c|}
\hline & $\begin{array}{l}\cdots \\
\quad \text { L. } 36.8\end{array}$ & L. 48 & M.12 & M.32 & \\
\hline $\mathrm{SiO}_{2}$ & 57,02 & 55,56 & 60,46 & 70,40 & $\mathrm{SiO}_{2}$ \\
\hline $\mathrm{TiO}_{2}$ & 0,69 & 0,21 & 0,77 & 0,33 & $\mathrm{TiO}_{2}^{2}$ \\
\hline $\mathrm{Al}_{2} \mathrm{O}_{3}$ & 17,72 & 16,66 & 16,46 & 11,99 & $\mathrm{Al}_{2} \mathrm{O}_{3}$ \\
\hline $\mathrm{Fe}_{2} \mathrm{O}_{3}^{3}$ & $9,96^{*}$ & 1,03 & $7,37^{*}$ & 4,00 & $\mathrm{Fe}_{2} \mathrm{O}_{3}^{3}$ \\
\hline $\mathrm{FeO}$ & - & 5,55 & - & 0,90 & $\mathrm{FeO}$ \\
\hline $\mathrm{MgO}$ & 0,27 & 1,20 & 4,38 & 0,49 & $\mathrm{MgO}$ \\
\hline $\mathrm{MnO}$ & 0,01 & 0,03 & 0,05 & 0,01 & $\mathrm{MnO}$ \\
\hline $\mathrm{CaO}$ & 0,80 & 0,51 & 1,31 & 0,33 & $\mathrm{CaO}$ \\
\hline $\mathrm{Na}_{2} \mathrm{O}$ & 1,11 & 0,55 & 1,53 & 0,20 & $\mathrm{Na}_{2} \mathrm{O}$ \\
\hline $\mathrm{K}_{2} \mathrm{O}$ & 3,80 & 4,74 & 1,81 & 1,79 & $\mathrm{~K}_{2} \mathrm{O}$ \\
\hline $\mathrm{P}_{2}^{2} \mathrm{O}_{5}$ & 0,56 & 0,06 & 0,12 & 0,24 & $\mathrm{P}_{2}^{2} \mathrm{O}_{5}$ \\
\hline $\mathrm{BaO}$ & 0,40 & 3,62 & 0,12 & 0,70 & $\mathrm{BaO}^{2}$ \\
\hline $\mathrm{Cu}$ & - & 0,48 & - & 0,97 & $\mathrm{Cu}$ \\
\hline W & - & - & - & 0,27 & W \\
\hline As & ـــ & - & - & 0,06 & As \\
\hline $\mathrm{Zn}$ & Traços & 2,28 & - & 4,70 & $\mathrm{Zn}$ \\
\hline L.O.I. & 8,17 & 5,66 & 5,12 & 1,90 & L.O.I. \\
\hline Total & 100,51 & 98,14 & 99,50 & 99,28 & Total \\
\hline
\end{tabular}

* Fe total como $\mathrm{Fe}_{2} \mathrm{O}_{3}$

L..36.8 - Quartzo-sericita xisto, testemunho da sondagem 10-807, Mina Lynx, zona do conduto.

L.48 - Quartzo-sericita-barita xisto, testemunho da sondagem 10-807, Mina Lynx, zona do flanco.

M.12 - Clorita-quartzo-carbonato-sericita xisto, Myra open pit. Contém esferulitos parcialmente substituidos por quartzo.

M.32 - Quartzo-sericita xisto silicificado, galeria Myra 12 K-124 (zona do conduto),

Elementos maiores determinados por fluorescência de raios $\mathrm{X}$.

FeO determinado por titulação volumétrica.

$\mathrm{Cu}, \mathrm{W}$, As e $\mathrm{Zn}$ determinados por absorção atômica. 


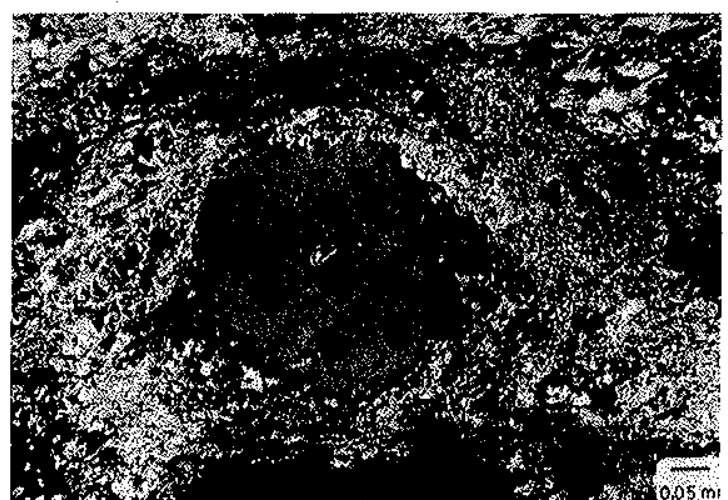

Figura 5 - Grão olho de-quartzo com fino núcleo de calcita preservado. Matriz de composição quartzo-sericitica. Zona do conduto. Mina Lynx. NX

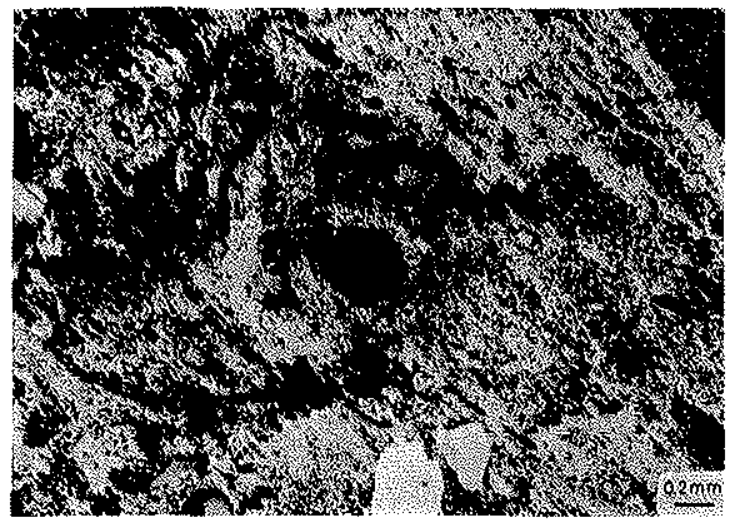

Figura 7 - Grão olho-de-quartzo (centro) em matriz quartzosericitica contendo grãos quebrados de quartzo original (campos claros na parte inferior) e sulfetos (maior parte das areas irregulares negras). Porção superior da zona do conduto. Myra open pit. Quase NX

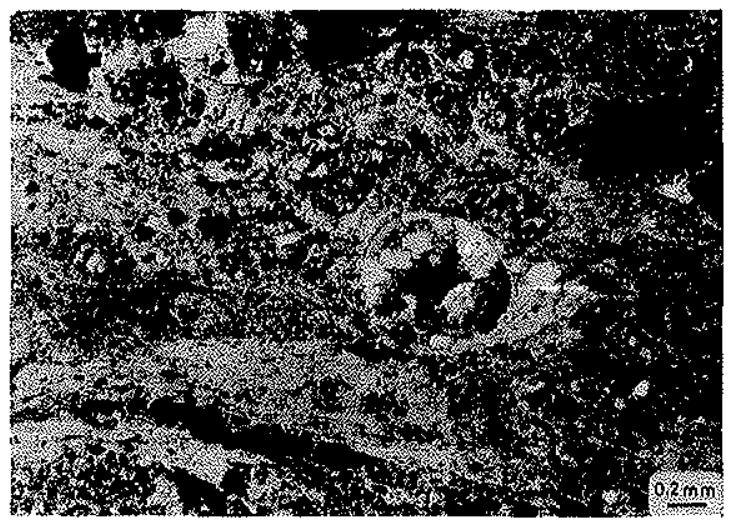

Figura 9 - Grão olho-de-quartzo parcialmente desenvolvido (centro) correspondendo à substituição parcial de um esferulito de calcita, clorita e epidoto por quartzo. A matriz é composta de sericita, clorita, quartzo, epidoto e sulfetos. Zona transicional. Mina Lynx. NX

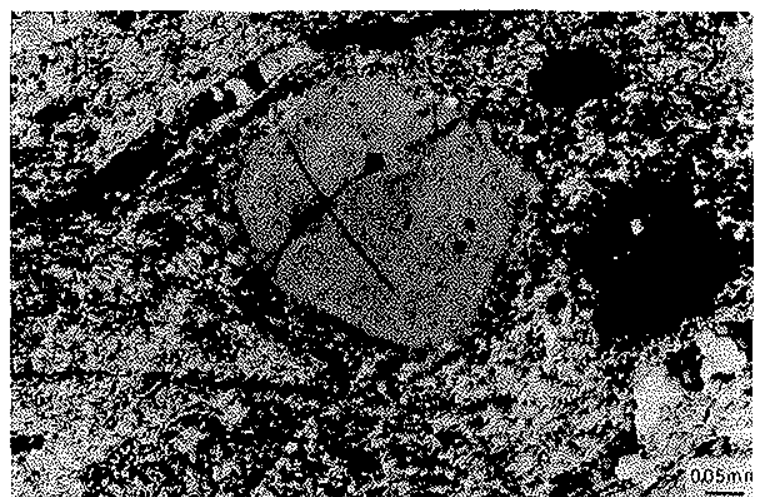

Figura 6 - Grão olho-de-quartzo em matriz quartzo-sericitica contendo clorita (manchas negras à direita) e vênulas 'de quartzo-calcita (direita, vértice inferior) e de quartzo-calcita e sulfetos (esquerda, parte superior). Zona do conduto. Mina Lynx. NX

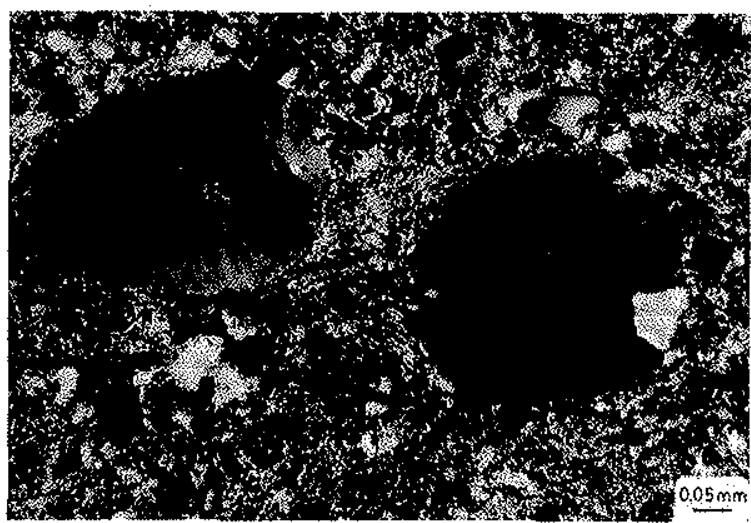

Figura 8-Grãos olhos-de-quartzo compostos e arrendondados em matriz quartzo-sericítica contendo cubos de pirita. $\mathrm{O}$ grão maior de quartzo componente do grão olho-de-quartzo da esquerda contém uma diminuta inclusão de calcita e epídoto de grã-fina (material remanescente). Zona do conduto. Mina Lynx. NX

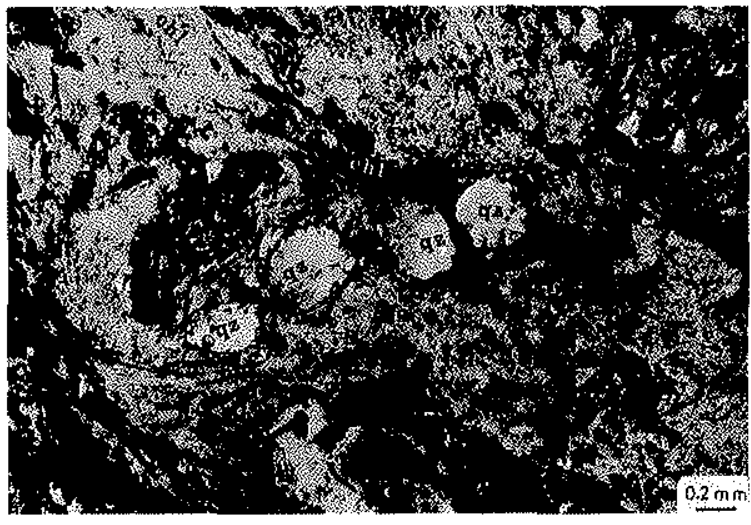

Figura 10 - Esferulitos de quartzo $(q z)$ em uma matriz de clorita $(c h l)$, quartzo, sericita e pouca pirita. Zona transicional. Mina Myra. Quase NX 


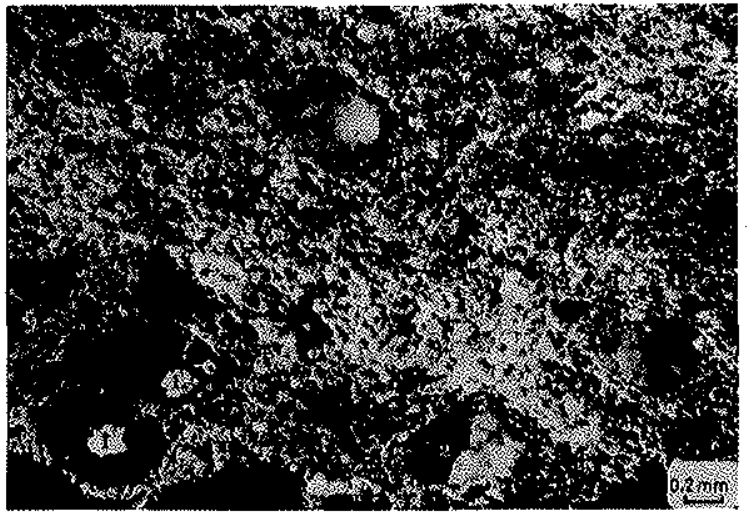

Figura 11 - Grãos olhos-de-quartzo em matriz quartzosericitica contendo sulfetos (predominantemente pirita). Grão arredondado (parte superior), grãos compostos com núcleo de calcita (I) e grão composto (2). Zona do conduto. Mina Lynx. NX

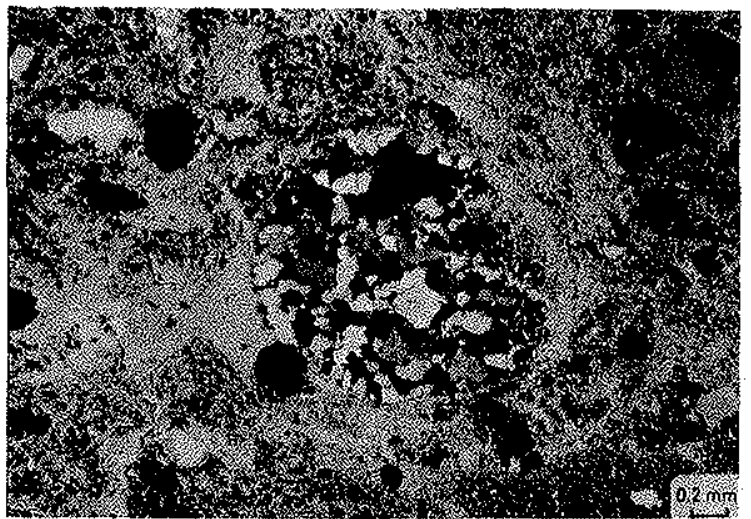

Figura 13 - Grão olho-de-quartzo composto e arredondado contendo pirita: Matriz quartzo-sericítica contendo quartzo primário (direita, vértice superior) e sulfetos (predominantemente grãos euedrais de pirita). Zona do conduto. Mina Myra. Quase NX

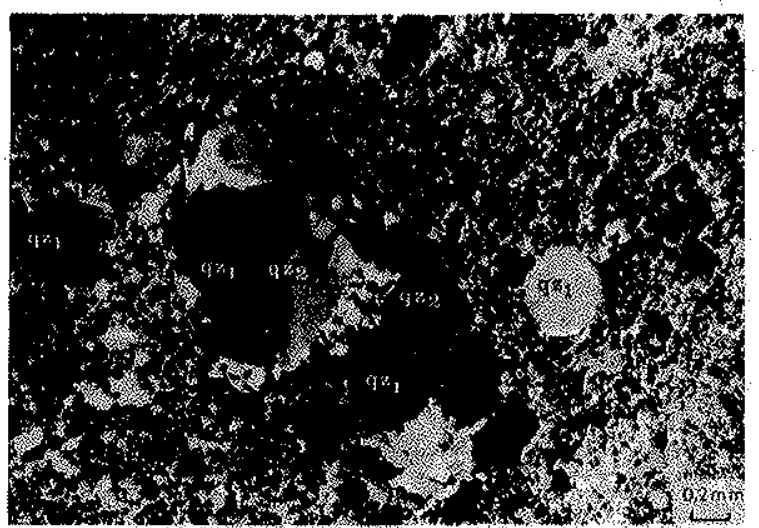

Figura 15 - Grãos olhos-de-quartzo arredondados de primeira geração $(q z$;) alguns intercrescidos com quartzo de segunda geração $\left(q z_{2}\right)$ em matriz quartzo-sericítica contendo pirita e esfalerita. Zona do conduto. Mina Lynx. NX

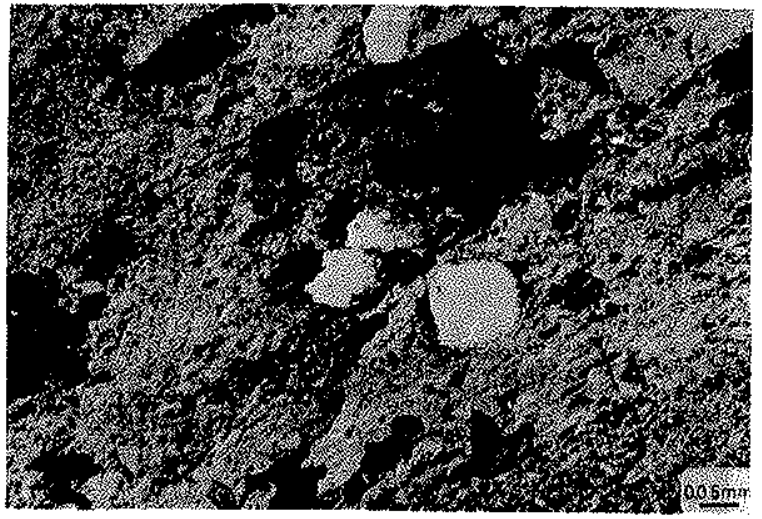

Figura 12 - Grãos olhos-de-quartzo subpoligonizados em matriz quartzo-sericitica contendo sulfetos (areas negras). Zona do conduto. Mina Lynx. Nicóis a $65^{\circ}$

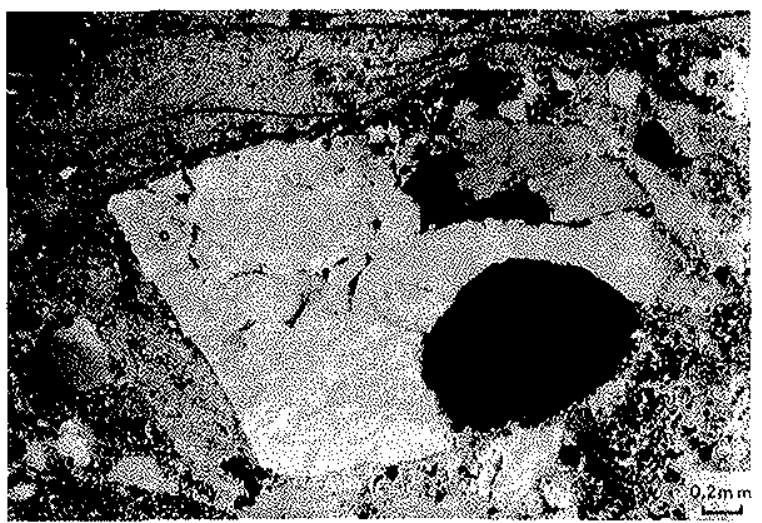

Figura 14 - Grão olho-de-quartzo formado de intercrescimento de grão esférico de quartzo de primeira geração (área negra maior) e quartzo de segunda geração. Matriz quartzosericitica contendo pirita (áreas negras menores) e esferulitos de quartzo. Amostra GHK (seção 4 da Fig. 30)

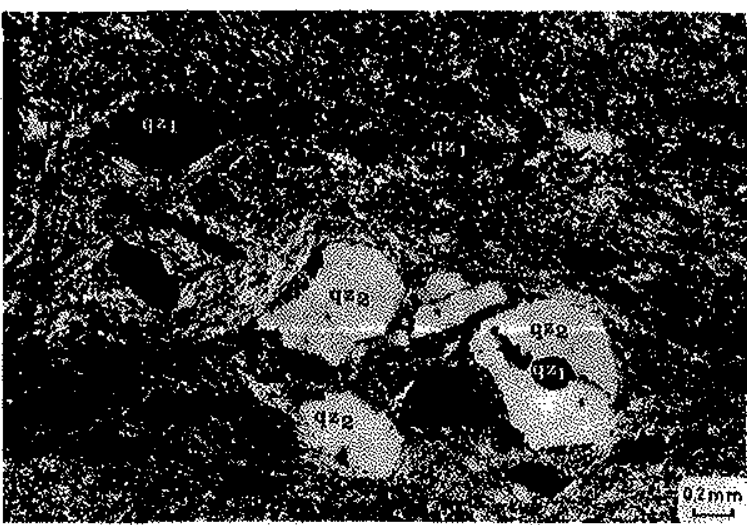

Figura 16 - Grãos olhos-de-quartzo de primeira geração $\left(q z_{l}\right)$ e quartzo de segunda geração $\left(q z_{2}\right)$. Intercrescimento desses dois tipos pode ser observado no grão da parte inferior, à direita, na foto. Matriz quartzo-sericítica contendo sulfetos (maior parte das áreas negras). Zona do conduto. Mina Lynx. NX 
As duas figuras mostram uma sequência de microfotografias de rochas coletadas em um perfil de amostragem transversal à parte superior da zona do conduto de Myra open pit. Tal seqüência evidencia a crescente substituiçăo de esferulitos de calcita, epídoto e clorita por quartzo.

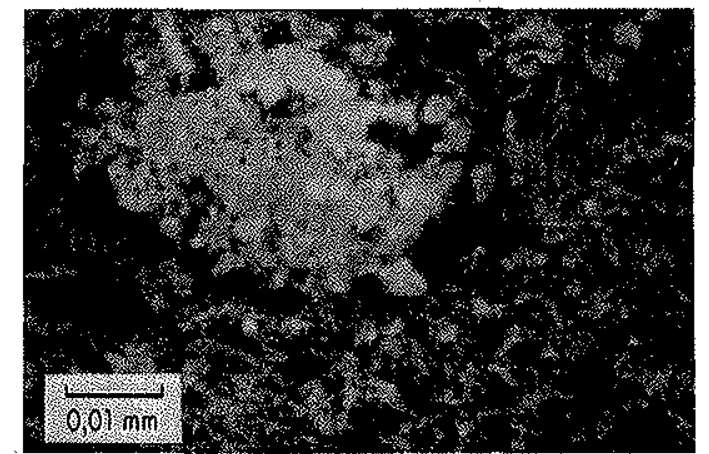

Figura $17 A-O$ esferulito contém pouco quartzo. Uma zona exterior de clorita (porçao externa escura do esferulito) é bem delimitada. Matriz predominantemente composta de clorita e calcita. Unidade Tuff, Quase NX

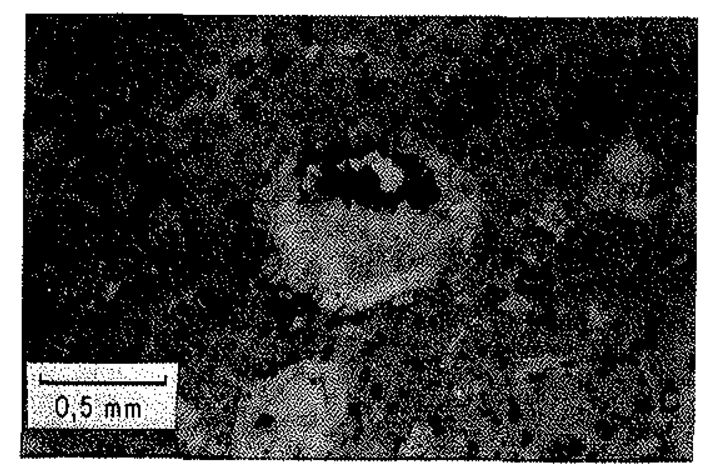

Figura $17 \mathrm{C}-$ Idem em luz plana (foto girada de $180^{\circ}$ )

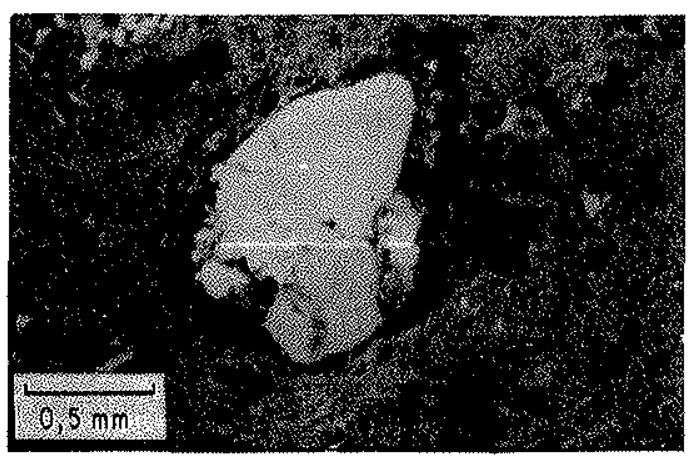

Figura $18 A-$ Esferulito quase que inteiramente substituido por quartzo. Clorita fina reveste a porção exterior quartzocalcifera do esferulito. Matriz quartzo-sericítica com calcita e clorita como acessório. Zona de transição. Nicóis a $55^{\circ}$

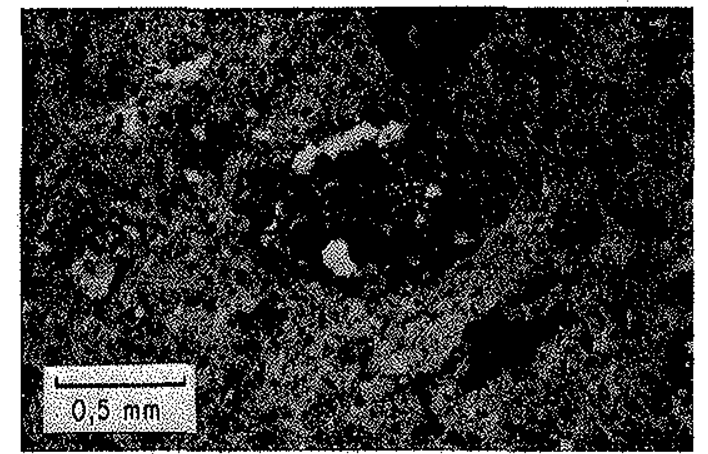

Figura $17 B-O$ esferulito (centro) contém mais quartzo que o tipo da Fig. 17 $\mathrm{A}$. O quartzo é mais grosseiro na periferia do esferulito. Matriz composta de clorita, quartzo, sericita e pouca $(<3 \%)$ calcita e epídoto $(\sim 2 \%)$. Zona transicional NX

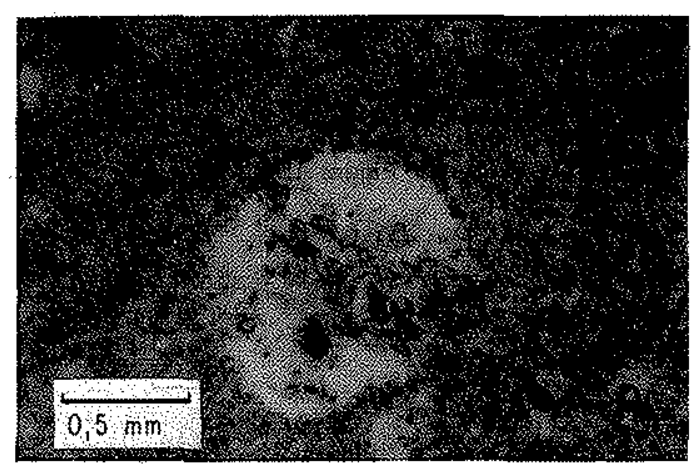

Figura $17 D$ - Esferulito com a porção exterior quase que inteiramente substituída por quartzo. Matriz composta predominantemente de sericita e quartzo, com clorita $(7 \%)$, calcita $(3 \%)$ e traços de epidoto. Pirita perfaz cerca de $3 \%$. Zona de transição. Luz plana

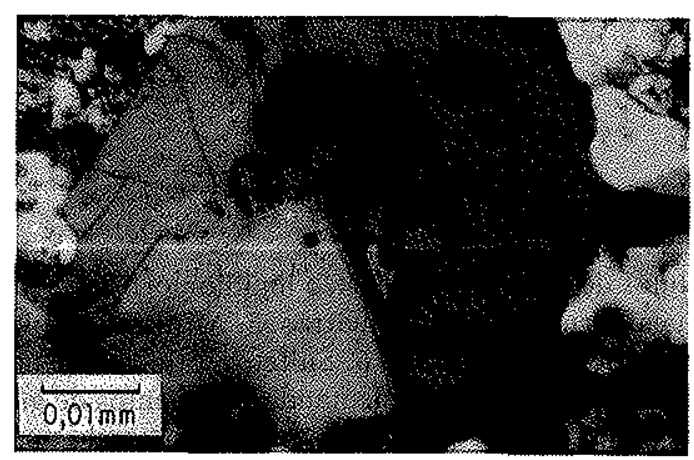

Figura $18 B$ - Esferulito de quartzo com calcita e epídoto muito finos preservados em seu interior. Observar a recristalização incipiente de grãos de quartzo em torno do esferulito. Zona do conduto. Quase NX 


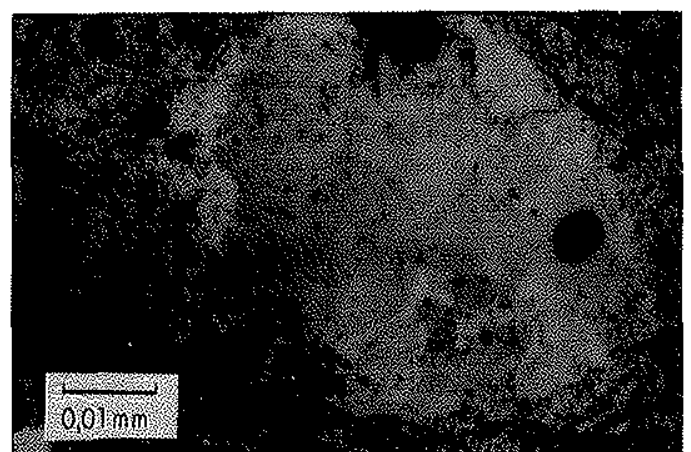

Figura $18 C$ - Esferulito de quartzo com alguma clorita e calcita em sua porção mais exterior. Matriz quartzo-sericítica contendo clorita $(<3 \%)$ e pirita $(<2 \%)$. Zona do conduto. Nicóis quase paralelos

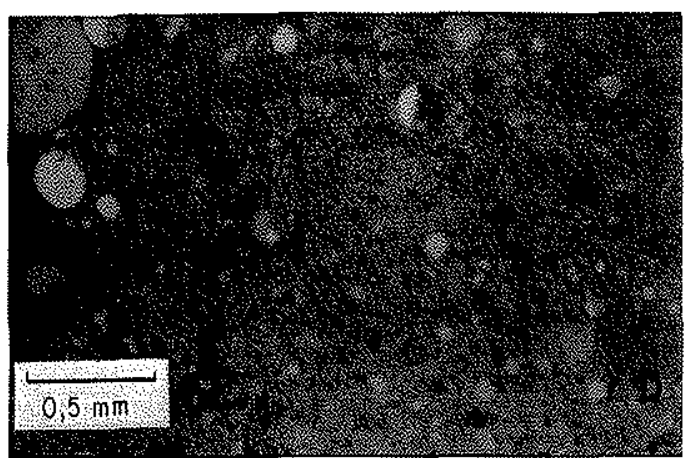

Figura $18 D$ - Esferulitos de quartzo disseminados em uma matriz quartzo-sericítica contendo sulfetos $(<5 \%)$. Observar a textura esferulítica em que as diferentes dimensőes dos esferulitos são mais resultantes de diferentes seções que de diferentes diâmetros dos mesmos. A seção do grão no vértice superior esquerdo foi a de maior dimensão observada para a lâmina delgada estudada. Zona do conduto. Nicóis quase paralelos

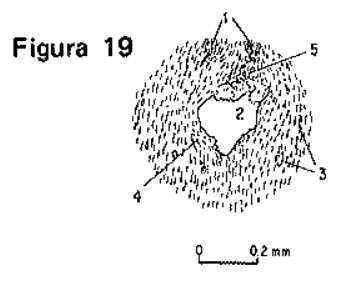

Figura 22

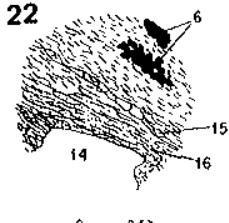

Figura 25

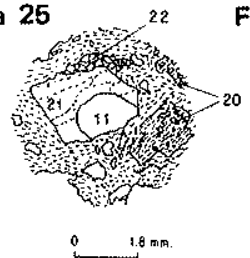

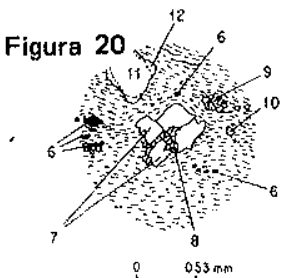

Figura 23

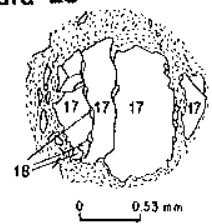

Figura $26_{12}$

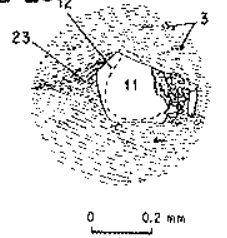

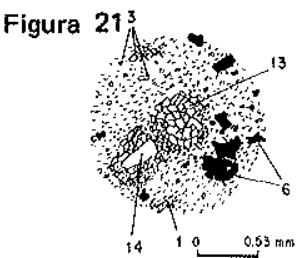

Figura 24

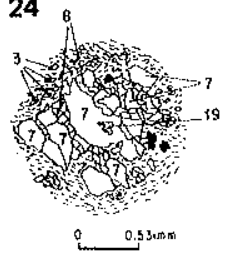

Figura 27

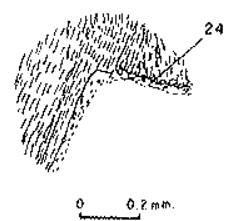

1. Nódulos de sericita. 2. Quartzo hipidiomórfico de primeira geração. 3. Quartzo fino de primeira geração. 4. Matrix micácea ar queada em torno de grão de quartzo. 5. Mistura complexa de quartzo, sericita e traços de clorita. O quartzo é opticamente contínuo em relação ao grão principal. 6. Sulfetos, principalmente pirita. 7. Grão de quartzo quebrado de primeira geração. 8. Quartzo de segunda geração como que cimentando fragmentos de grão de primeira geração. 9. Pequeno agregado de quartzo contendo mica intersticial. 10. Grão de quartzo talvez representando uma pequena seção de um grão maior de quartzo. 11. Quartzo arredondado de primeira geração. 12. Anel de quartzo opticamente contínuo ao grão central de primeira geração. 13. Grão composto framboedal de primeira geração. 14. Grão primário de quartzo. 15. Grão achatado composto de quartzo de primeira geração. 16. Mistura de quartzo fino e sericita em torno de grão primário de quartzo. 17. Grão de quartzo de primeira geração microfraturado. 18. Grãos de crescimento subordinado e cimento de quartzo de segunda geração. 19. Inclusão de clorita-calcita-epídoto em quartzo de primeira geraçâo. 20. Massa idiomórfica de sericita pseudomórfica de feldspato. 21. Crescimento hipidiomórfico de quartzo de segunda geração sobre quartzo de primeira geração. 22. Grão composto de quartzo de primeira geração. 23. Vassourinha de sericita. 25. Falso anel de crescimento de quartzo sobre um grão hipidiomórfico de quartzo de segunda geração 
Tabela 2 - Listagem para quartzo de primeira geração

$*$ DATA CARD $1 * * *$ CONTROL CARD $*$ KONT $(1-4)=2000 \mathrm{KARD}=0$ NSTEP $=0$ DIAM $=0.00$ GRID $=$ 0.00

MESSAGE $=$

IMESS $=0$

* DATA CARD $2 * * *$ TITLE CARD * TITLE $=$ C-AXIS VERT. SECTION PERP. TO CLEAVAGE PLANE

* DATA CARD $4 * *$ CONTOUR DATA ${ }^{*}$ CONT $(1-16)=1.02 .03 .04 .05 .06 .07 .08 .09 .0 .01 .02 .03 .04 .05 .00 .0$

THE MAXIMUM CONCENTRATION $=6$ POINTS.

PERCENTAGE OF THE AREA OF THE PROJECTION COVERED BY DIFFERENT CONCENTRATIONS OF POINTS FOR FIRST GENERATION QUARTZ

O POINT CONCENTRATION COVERS 39.93 PERCENT OF THE AREA OF THE PROJECTION 1 POINT CONCENTRATION COVERS 34.06 PERCENT OF THE AREA OF THE PROJECTION 2 POINT CONCENTRATION COVERS 15.81 PERCENT OF THE AREA OF THE PROJECTION 3 POINT CONCENTRATION COVERS 5.94 PERCENT OF THE AREA OF THE PROJECTION 4 POINT CONCENTRATION COVERS 2.50 PERCENT OF THE AREA OF THE PROJECTION 5 POINT CONCENTRATION COVERS .71 PERCENT OF THE AREA OF THE PROJECTION 6 POINT CONCENTRATION COVERS .05 PERCENT OF THE AREA OF THE PROJECTION

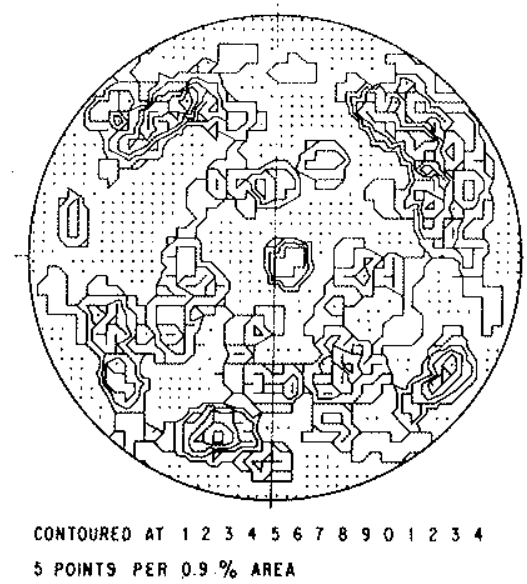

Figura 28 - Orientação do eixo $C$ em quartzo de primeira geração. Seção perpendicular ao plano de xistosidade

Tabela 3 - Listagem para quartzo de segunda geração

$*$ DATA CARD $1 * * *$ CONTROL CARD $* \operatorname{KONT}(1-4)=2000 \mathrm{KARD}=0 \mathrm{NSTEP}=0$ DIAM $=0.00 \mathrm{GRID}=$ 0.00

MESSAGE $=$

IMESS $=0$

* DATA CARD $2 * * *$ TITLE CARD * TITLE $=$ C-AXIS HORIZ. SECTION PERP. TO CLEAVAGE PLANE

* DATA CARD $4 * * *$ CONTOUR DATA * CONT $(1-16)=1.02 .03 .04 .05 .06 .07 .08 .09 .0 .01 .02 .03 .04 .05 .00 .0$

THE MAXIMUM CONCENTRATION $=8$ POINTS.

PERCENTAGE OF THE AREA OF THE PROJECTION COVERED BY DIFFERENT CONCENTRATIONS OF POINTS FOR SECOND GENERATION QUARTZ

O POINT CONCENTRATION COVERS 41.87 PERCENT OF THE AREA OF THE PROJECTION 1 POINT CONCENTRATION COVERS 32.38 PERCENT OF THE AREA OF THE PROJECTION 2 POINT CONCENTRATION COVERS 15.04 PERCENT OF THE AREA OF THE PROJECTION 3 POINT CONCENTRATION COVERS 7.60 PERCENT OF THE AREA OF THE PROJECTION 4 POINT CONCENTRATION COVERS 2.04 PERCENT OF THE AREA OF THE PROJECTION 5 POINT CONCENTRATION COVERS .41 PERCENT OF THE AREA OF THE PROJECTION 6 POINT CONCENTRATION COVERS .25 PERCENT OF THE AREA OF THE PROJECTION 7 POINT CONCENTRATION COVERS .36 PERCENT OF THE AREA OF THE PROJECTION 8 POINT CONCENTRATION COVERS .05 PERCENT OF THE AREA OF THE PROJECTION 


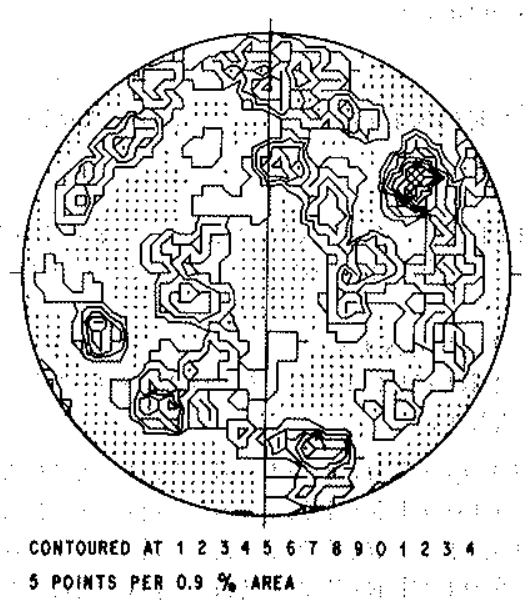

Figura 29 - Orientação do eixo $C$ em quartzo de segunda geração. Seção perpendicular ao plano de xistosidade e à lineação de xistosidade

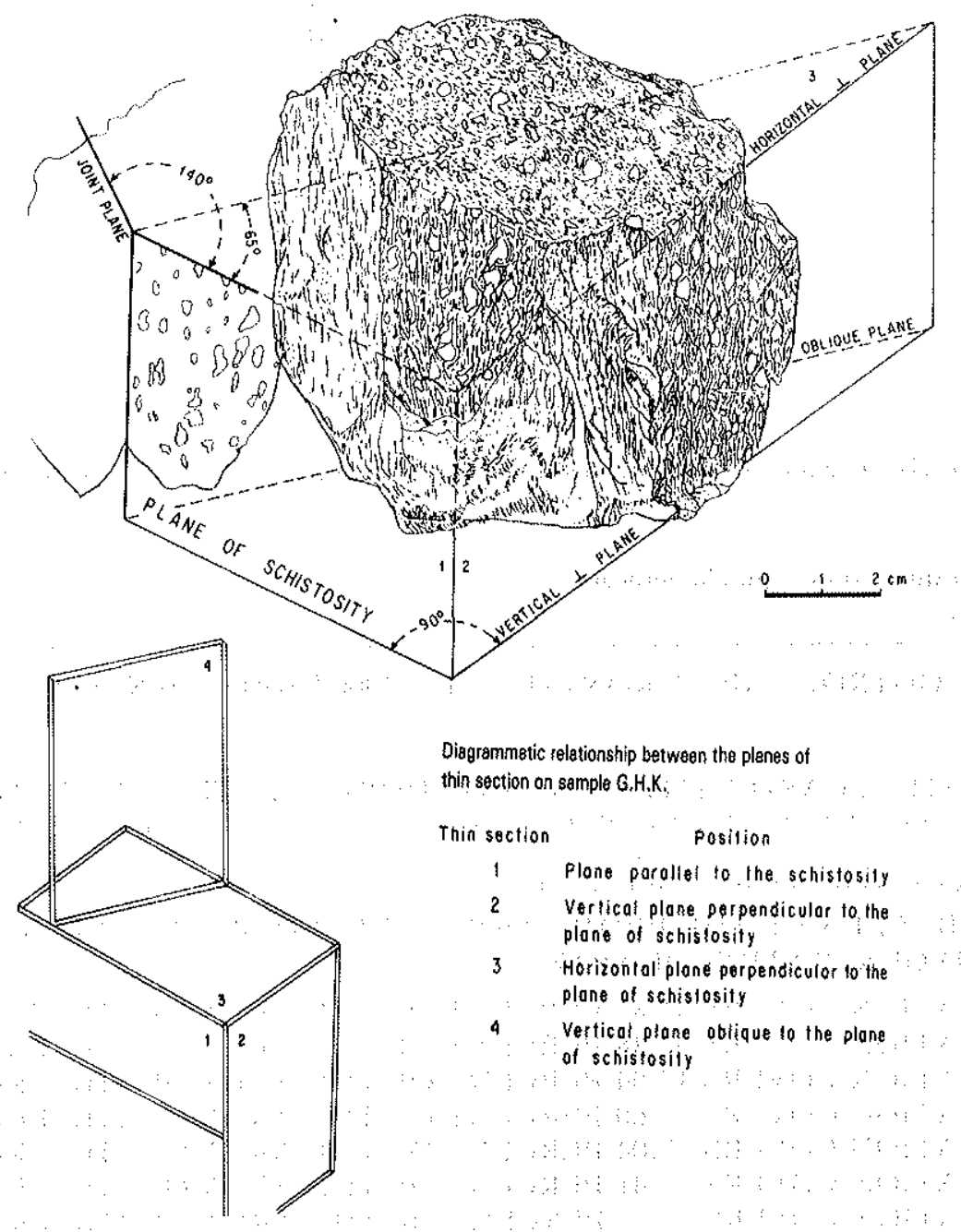

Figura 30 - Xisto porfiróide contendo olhos-de-quartzo. Amostra proveniente de Lynx 
Orientaçðes cristalográficas de quartzo $\mathrm{qz}_{1}$ e de quartzo $\mathrm{qz}_{2}$ foram determinadas para duas amostras provenientes de mina Lynx (Figs. 3 e 4). As determinações foram processadas em seções delgadas confeccionadas a partir das posições de corte como as ilustradas na Fig. 30 para a amostra GHK. As orientações dos eixos $C$ dos grãos de quartzo foram determinadas pelo método convencional da platina universal e os dados obtidos foram computadorizados segundo o método descrito por Starkey (1970 e 1977) para obtenção dos dados de orientação e das projeções esféricas. Os grãos reconhecidamente primários ou originais, e que são raros, não foram levados em consideração.

Apenas a título de ilustração reproduzimos neste trabalho os dados de orientação e as projeçðes esféricas para quartzo $\mathrm{qz}_{1}$ e quartzo $\mathrm{qz}_{2}$, respectivamente, examinados em seções delgadas de posiçóes de corte 2 e 3 na amostra GHK (Fig. 30). O significado da orientação cristalográfica fortuita desses grãos de quartzo será brevemente discutido no final do trabalho.

Também foi observado que, em relação ao plano vertical de xistosidade, conforme pode ser também observado na Fig. 30 , as rochas porfiroidais a olho-dequartzo não exibem a mesma fábrica na seção horizontal e que é perpendicular ao plano de xistosidade quando comparada com as demais seções. No primeiro caso, que corresponde à Seção 3 da Fig. 30, existe uma orientação quase que imperceptível da matriz micácea em torno dos grãos olhos-de-quartzo.

\section{CONSIDERAÇÕES DE ORDEM GENÉTICA}

Muitos tipos litológicos podem ser texturalmente semelhantes às rochas porfiroidais a olhos-de-quartzo, tal é o caso de alguns tectonitos, milonitos e quartzo-queratófiros de zonas de falhas e de cisalhamento. Em muitos casos, a semelhança é tão-só megascópica. Esses materiais possuem uma textura originada por pressðes mecânicas com remobilização local e recristalização de quartzo preexistente, presença de quartzo mortar e podendo ter fenocristais originais preservados. A rocha, normalmente, é bem foliada com transposição de planos e os grãos porfiroblastos, normalmente, mostram rotação ou deslocamentos. Tais rochas não são necessariamente tipos vulcânicos ou subvulcânicos. No caso de alguns tectonitos, elas são comuns em zonas de metamorfismo de grau anfibolítico e granulítico, identificando-se com os tipos denominados de augen gnaisses. Quartzo-sericita xistos porfiríticos derivados de quartzo-pórfiros e de riolitos porfiríticos, muitas vezes com grãos olhos, de até alguns milímetros de diâmetro e de tonalidade azulada, mostram semelhanças químicas e mineralógicas com as rochas porfiroidais a olhos-dequartzo. Do ponto de vista do autor, uma associação espacial dessas rochas porfiríticas primárias com rochas porfiroidais a olhos-de-quartzo seria possivel de ocorrer em determinadas áreas bastando para isso que tenhamos: $a$ ) um vulcanismo diferenciado de basalto-andesito a riolito; $b$ ) vulcanismo submarino e uma fonte termal em ascensão (hot plume); e c) formação de células hidrotermais convectivas por mecanismos como os descritos por Elder (1965), e Vine e Moores (1972).
Shrock (1948, p. 381) sugeriu que os grãos olhos-dequartzo presentes nos basaltos em almofadas do fácies arqueano Keewatin do cinturão de rochas verdes do Abitibi (Canadá) seriam resultantes de preenchimento por quartzo de bolhas gasosas trapeadas nessas rochas.

Hopwood (1976) propôs uma origem complexa para as rochas porfiroidais com olhos-de quartzo. Ele admitiu que tal origem estaria relacionada ao contínuo crescimento metassomático dos grãos olhos dentro de uma matriz que é ativa e continuamente deformada em relação à fase de deformação que ele caracterizou como $S_{2}-L_{2}$. Ele sugeriu que as rochas porfiroidais a olhos-dequartzo, provavelmente, representam materiais ácidos (acid melts) que se intrudiram por meio de uma ascensão vertical durante a fase $S_{2}-L_{2}$ de deformação. Hopwood parece admitir um material fundido salino, rico em íons de elementos alcalinos, tipo salmoura, quando também ele se refere a esses acid melts como brine melts. Devido à rápida ascensão do brine melt, $\mathrm{e}$ do conseqüente alívio de pressão e de temperatura, haveria uma liberação e expulsão da sílica. Algumas críticas no mecanismo de colocação do material fundido ascendente, como propôs Hopwood, foram feitas por Vernoon e Flood (1977), sobretudo no que se refere ao processo de desenvolvimento de um porfiroblasto no estado sólido.

As características que nos levam a considerar metassomatismo hidrotermal como responsável pela formação dos olhos-de-quartzo nas rochas do conduto (unidade Vent) do Distrito de Western Mines são:

a) As rochas vulcânicas longe do conduto (isto é, rochas da unidade Tuff) foram afetadas por deformaçðes menores ou, aparentemente, nenhuma. Os bandamentos primários, indicados nas ilustrações como coincidentes com $S_{0}-L_{0}$, estão bem preservados.

b) As rochas, como em $a$, estão propilitizadas sendo que, em termos de mineralogia, a paragênese é predominantemente secundária (clorita, calcita, epídoto e feldspato albitizado) representando um espectro dos minerais originais. Estudos detalhados do autor (Carvalho, 1979) indicaram que essas rochas da unidade Tuff foram predominantemente derivadas de rochas de composição basalto-andesítica, andesíticas e dacíticas.

c) A alteração propilítica não está aparentemente relacionada ao processo de mineralização pelo fato de ela afetar rochas estratigraficamente acima e abaixo do minério do flanco (Carvalho, 1979).

d) Vênulas, lentezinhas e vesículas, contendo calcita, clorita e, subordinadamente, epidoto, são feiçðes comuns nos tipos litológicos da unidade Tuff. A presença de sulfeto restringe-se a traços de pirita cujo teor raramente atinge $1 \%$.

e) Uma foliação vertical, indicada nas ilustrações como coincidente com $S_{1}-L_{1}$, é observada nas rochas da unidade Tuff e gradualmente aumenta de intensidade em direção à zona do conduto paralelamente com o aumento da silicificação. Como resultado, o bandamento primário é quase que totalmente destruído e uma zona transicional entre as rochas da unidade Vent e da unidade Tuff torna-se necessária de ser definida. 
f) $\mathrm{O}$ processo de silicificação é diagnosticado - no campo, pela presença de quartzo, às vezes com aspecto jesperoidal, preenchendo planos de juntas e de fraturas - no laboratório pela ocorrência de quartzo nos esferulitos e presença de venulazinhas de quartzo e quartzo-calcita, sendo que em direção ao conduto o quartzo tende a aumentar gradativamente em teor, e a calcita, a clorita e o epídoto, paralelamente a diminuir.

O processo contínuo de alteração do conduto e zona de alteração não foi homogêneo. A heterogeneidade é resultante da diferente intensidade de atuaçăo das soluçôes hidrotermais no tempo e no espaço. Essa intensidade depende de muitos fatores cuja caracterização foge aos escopos deste trabalho. Desde então, correntes convectivas de águas marinhas aquecidas por uma fonte termal subvulcânica alteraram não-homogeneamente as rochas do conduto e, como conseqüência, é de se admitir que rochas menos silicificadas, contendo alguma clorita, calcita e epídoto, poderiam restar no conduto, mesmo nas vizinhanças ou junto de quartzo-sericita xistos (incluindo aqui as rochas porfiroidais e olhos-de-quartzo e as variedades afaniticas) (Fig. 31). O conceito de quartzo de primeira geração e de segunda geração seria, pois, um tanto relativo desde quando no espaço global de alteração hidrotermal, em um dado local, o quartzo de segunda geração poderia estar sendo formado ao tempo em que, em outro local que está sendo pela primeira vez percolado pelas soluçðes ascendentes, teríamos a formação de quartzo de primeira geração. Baseando-se neste raciocínio, torna-se difícil especificar: a) se na zona de transição o quartzo presente, de primeira geração, foi todo ele depositado sincronicamente ou se em períodos distintos; e b) qual o tempo de sua deposição em relação às deposições de ambos os quartzos de primeira e de segunda geração na zona do conduto propriamente dito.

A orientação cristalográfica fortuita do quartzo, seja ele formado na fase inicial $\left(q z_{1}\right)$ ou em fases avançadas $\left(q z_{2}\right)$ do processo de silicificação, demonstra que as forças finitas atuantes durante seus desenvolvimentos não foram homogêneas nem no tempo nem no espaço, e que os efeitos mecânicos foram neglegíveis.

Numa tentativa de interpretar a gênese dâ mineralização de $\mathrm{Pb}-\mathrm{Zn}$-Cu-Ag-Au-Cd do Distrito de Western Mines, o autor (Carvalho, 1979) sugeriu que a salmoura hidrotermal silicosa, ou solução mineralizante, resultou de um sistema convectivo de águas submarinas perco. lantes às rochas vulcânicas pré-alteradas (palagonizadas) e aquecidas nas vizinhanças de uma zona linear falhada de extrusão (zona do conduto). As trocas químicas sofridas por esta salmoura hidrotermal durante sua rápida ascensão na zona do conduto seria um fator importante no processo de liberação da sílica. Um decréscimo de $\mathrm{pH}$ durante a sericitização do material feldspático (Fig. 25) das rochas vulcânicas palagonizadas poderia causar ou contribuir com a liberação da sílica da salmoura. $O$ autor concluiu por uma alteração inicial tipo palagonização por meio de comparaçðes e analogias com litologias resultantes de extrusões submarinas e alteradas pelo intemperismos subaquático.

Furnier (1968) sugeriu que a ascensão rápida e mesmo explosiva de fluidos hidrotermais pode ocorrer em zonas falhadas de baixa pressão. De fato, tais zonas podem atuar como zonas de alívio de pressão em regiøes
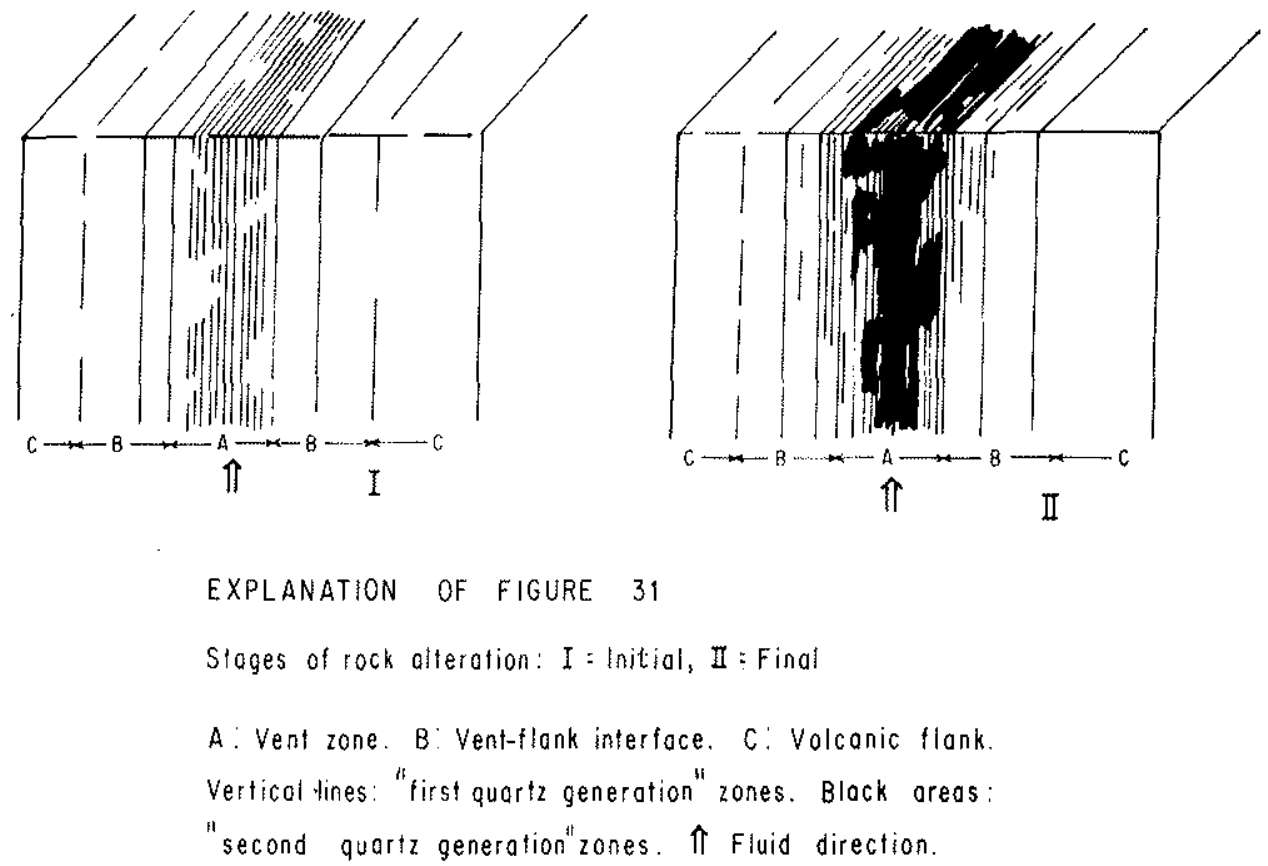
de vulcanismo ativo. $O$ alívio de pressão pode ser de forma rápida (erupções explosivas, terremotos) ou lenta (fontes quentes, fumarolas e dobramentos). Em ambos os casos, soluçðes hidrotermais poderiam ascender-se. Sibson et al. (1975) sugeriu que, antes de um movimento sísmico ocorrer ao longo de uma falha existente, a área adjacente à falha e circunvizinha ao foco sísmico sofrerá uma dilatação em conseqüência das tensðes ascendentes por aparecimento de juntas e fraturas de extensão. $\mathrm{O}$ aparecimento dessas fraturas e juntas na zona dilatante é o fator principal da migração ascendente do material hidrotermal convectivo. Este mecanismo, conhecido como bombeamento tectônico (tectonic pumping), parece ser ajustável para explicar a migração ascendente de fluidos através de extensas zonas de fraturas e de cisalhamento.

Agradecimentos $\mathrm{O}$ autor agradece $\mathrm{O}$ suporte da Canadian International Development Agency (CIDA), da Western Mines Limited e ao Dr. J. Starkey da Universidade de Western, Ontário.

\section{BIBLIOGRAFIA}

CARVALHO, 1. G. - 1979 - Geology of the Western Mines District, Vancouver Isłand, Britisł Columbia. Tese de doutoramento (inédita), U.W.O., Londres, Canadá.

ELDER, J. W. - 1965 - Physical processes in geothermal areas. Am. Geophys. Union, Monogr. Ser., 8, pp. 211-239.

FURNIER, R. O. - $1968-$ Depths of intrusion and conditions of hydrothermal alteration in porphyry copper deposits. Geol. Soc. Am. Ann. Meeting; Programs with abstract, pp. 101.

HOPWOOD, T. P. - 1976 _- "Quartz eye" - bearing porphyroidal rocks and volcanogenic massive sulphide deposits. Econ. Geol. 71, pp. 589-612.

JONES, D. L., SILBERLING, N. J. e HILLOUSE, J. - 1977 - Wrangellia-A Displaced terrane in northwestern North America, Can. J. Earth Sci. 14, pp. 133-150.

SERAPHIM, R. H., PEARSON, C. A. e TSCHACH, R. K. - 1978 - Western Mines Myra, Lyns and Price Deposits. CIM. Abstract of presentation. CIM 80ih. Ann, Gen, Meeting, Vancouver, CIM 71, pp. 106.

SHROCK, R, R - - 1948 - Sequence in layred rocks: a study of features and structures useful for determining top and bottom or order of succession in bedded and tabular rock bodies. McGraw-Hill Book Co., New York, $\$ 07$

SIBSON, R, H. et al. - 1975 - Seismic pumping - a hydrothermal flutd trang port mechanism. J. Geol, Soc, London 131, pp. 653 659 .

SPENCER, B. E. - 1974 - Geology of Western Mines Ltd. Notes from prosentation at G.A.C. Cordillera Section, Annual Meeting, feveretro do 1974 ,

STARKEY, J. - 1970 - A computer programme to prepare orlentation dia grams Experimental and Natural Rock Deformation. Springer-Verlag, Berlim, pp. $51-74$.

STARKEY, J. -1977 - The contouring of orientation data representod in spherical projection. Can. J. Earth Sci. 14, pp. 268-277.

VERNON, R. H. e FLOOD, R, H. - 1977 - "Quartz-eye" bearing porphyrof dal Rooks and Volcanogenic Massive Sulphide Deposits $-\boldsymbol{A}$ discussion. Econ. Geol. 72, pp. 698-703.

VINE, F. J. e MOORES, E. M. - 1972 - A model for the gross strueture, petrology and magnetic properties of oceanic crust. Geol, Soc. Am, Menn. 132, pp, 195-205. 